\title{
The changing landscape of phase II/III metastatic sarcoma clinical trials-analysis of ClinicalTrials.gov
}

\author{
Y Que ${ }^{\dagger}$, W Xiao $^{\dagger}$, BS Xu ${ }^{\dagger}$, XZ Wen, DS Weng and X Zhang ${ }^{*}$
}

\begin{abstract}
Background: Well-designed clinical trials are of great importance in validating novel treatments and ensuring an evidence-based approach for sarcoma. This study aimed to provide a comprehensive landscape of the characteristics of metastatic or advanced sarcoma clinical trials using the substantial resource of the ClincialTrials. gov database.

Methods: We identified 260,755 trials registered with ClinicalTrials.gov in the last 20 years, and 277 of them were eligible for inclusion. The baseline characteristics were ascertained for each trial. The trials were systematically reviewed to validate their classification into 96 trials registered before 2008 and 181 trials registered between 2008 and 2017.

Results: We found that in the last decade, metastatic and advanced sarcoma trials were predominantly phase II-III studies ( $p=0.048)$, were more likely to be $\geq 2$ arms ( $17.7 \%$ vs $35.3 \%$, respectively; $p=0.007)$, and were more likely to use randomized ( $13.5 \%$ vs $30.4 \% ; p=0.002)$ and double-blinded ( $2.1 \%$ vs $9.4 \% ; p=0.024)$ assignment than trials registered before 2008. Furthermore, in the last 10-year period, metastatic sarcoma trials were more likely to be conducted in Asia. Treatment involving target therapy and immunotherapy were more common $(71.8 \%$ vs $37.5 \% ; p<0.001)$ than in previous years.

Conclusions: Our data showed provocative changes in the sarcoma landscape and demonstrated that the incidence of clinical trials with target therapy and immunotherapy is increasing. These findings emphasize the desperate need for novel strategies, including target therapy and immunotherapy, to improve the outcomes for patients with advanced sarcoma.
\end{abstract}

Keywords: Sarcoma, ClinicalTrials.gov, Target therapy, Immunotherapy, Landscape

\section{Background}

Bone and soft-tissue sarcoma is a heterogeneous group of many rare tumours that comprises more than 50 subtypes $[1,2]$. The incidence of soft-tissue sarcomas in the US is approximately 11,280 cases every year, and in Europe, the estimated incidence rate of sarcomas taken as a whole is 5 cases per 100,000 people per year [3]. Doxorubicin and ifosfamide remain the most effective chemotherapy drugs available for the first-line treatment of

\footnotetext{
* Correspondence: zhangxing@sysucc.org.cn

${ }^{\dagger}$ Yi Que, Wei Xiao and Bushu Xu contributed equally to this work.

Department of Medical Melanoma and Sarcoma, State Key Laboratory of Oncology in South China, Collaborative Innovation Center for Cancer Medicine, Sun Yat-sen University Cancer Center, 651 East Dongfeng Road, Guangzhou 510060, China
}

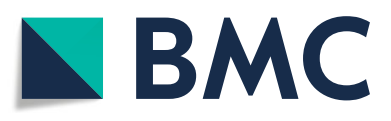

(c) The Author(s). 2018 Open Access This article is distributed under the terms of the Creative Commons Attribution 4.0 International License (http://creativecommons.org/licenses/by/4.0/), which permits unrestricted use, distribution, and reproduction in any medium, provided you give appropriate credit to the original author(s) and the source, provide a link to the Creative Commons license, and indicate if changes were made. The Creative Commons Public Domain Dedication waiver (http://creativecommons.org/publicdomain/zero/1.0/) applies to the data made available in this article, unless otherwise stated. advanced or metastatic sarcoma patients $[4,5]$. However, the prognosis and the long-term outcome remain unsatisfactory. Therefore, improvements in patient outcome and the development of new therapies for bone and soft-tissue sarcomas through clinical trials are urgently needed. In the last decade, we have witnessed the rapid development and success of precision medicine based on individual characteristics in sarcoma. Efforts have been made to develop targeted therapeutic agents that reflect specific molecular biology, from pazopanib, which has significantly increased progression-free survival by a median of 3 months compared with placebo [6], to a great improvement in overall survival and acceptable toxicity in patients treated with olaratumab with doxorubicin. 
Additionally, immunotherapeutic approaches in sarcoma hold substantial potential, from Coley's toxin to adoptive cell therapy $[7,8]$. Thus, the advances of promising approaches have ushered in an era of innovative therapies. In the present study, we aimed to explore the landscape of clinical trials of sarcoma over time to better understand what changes in clinical trial design have been made and the trends of new therapies for sarcoma over the last 2 decades.

We reviewed all the metastatic phase II/III bone and soft-tissue sarcoma clinical trials present on ClinicalTrials.gov. The ClinicalTrials.gov website is the largest clinical trial registry, with over 200,000 trials, and is a publicly available database that was developed and is maintained by the National Library of Medicine [9]. In 2007, Congress expanded ClinicalTrials.gov by requiring additional trial information [10]. Because phase I trials have focused on the safety of systemic treatments and not as much on potential innovations in the medical treatment process, we restricted the present analysis to phase II and III clinical trials for sarcoma registered on ClinicalTrials.gov. We sought to describe the emerging landscape and characteristics of such metastatic or locally advanced sarcoma phase II and III trials conducted within the last 2 decades.

\section{Methods}

\section{Creation of the ClinicalTrials.gov dataset}

On December 7, 2017, a dataset of 260,755 studies registered on ClinicalTrials.gov was downloaded. We queried ClinicalTrials.gov for the term "sarcoma" in the short titles, scientific titles, conditions, short summaries and detailed descriptions. Using this search strategy, 1494 trials were identified. We restricted our search to interventional trials and trials in phases II and III with a "known" status. We excluded trials with multiple tumour entities or that were non-sarcoma specific as well as those in a terminated/suspended or withdrawn status. Kaposi's sarcoma, paediatric sarcoma, gastrointestinal

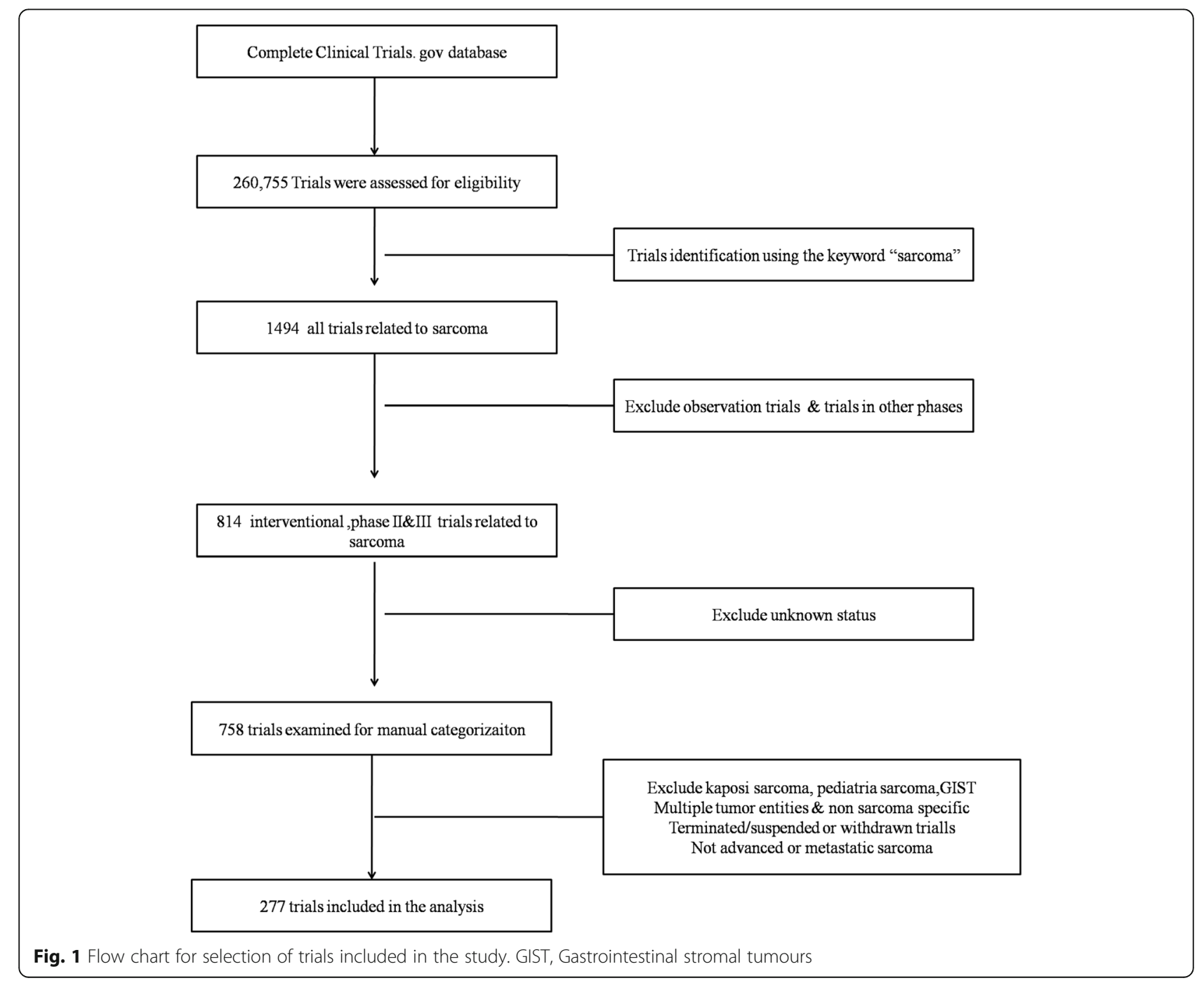


stromal tumor (GIST) and sarcomas that were not advanced or metastatic were also excluded. After examination for manual categorization, 277 trials were selected for analysis. The trial selection process is shown in Fig. 1.

The extracted data elements included the following: phase (II-III), sponsor, study site locations, conditions (disease type), interventions, enrolment, study design, trial start date, and number of participating centres. The sponsor type (NIH, industry or other) for each trial was determined using a previously published algorithm [11].

All the registered trials were classified according to their specific treatment and were divided into four groups: those using a targeted drug, those using immunotherapy, those using chemotherapy and others. The treatments were categorized based on the resources available in the following databases: www.drugbank.com [12], pubchem.ncbi.clm.nih.gov, the National Cancer Institute Dictionary of Cancer Terms (www.cancer.gov), the Scopus database, the PubMed Database, and Google Scholar. Because of data unavailability, we manually classified the drugs according to the WHO guidelines. In addition, the specific target receptors were also investigated and noted.

\section{Statistical analysis}

A descriptive analysis was performed to provide an overview of the emerging landscape of metastatic and advanced phase II and III sarcoma clinical trials registered on ClinicalTrials.Gov. The characteristics of the trials conducted between 2008 and 2017 were compared with those conducted before 2007 using Chi-squared or Fisher's exact tests. All the data were analysed using SPSS 18.0. All $p$-values were 2-tailed with significance defined as $p<0.05$.

\section{Results}

\section{Clinical trial characteristics}

Of the initial 260,755 trials identified, 277 were eligible for inclusion in the analysis. The reasons for exclusion are shown in Fig. 1. Trial names with ClinicalTrials.gov identification numbers are listed in the supplemental data for eligible trials in this study (Additional file 1). The trial design characteristics are presented in Table 1. Of the metastatic or advanced sarcoma trials with a sponsor, $11.9 \%$ were sponsored by NIH, $21.7 \%$ were sponsored by industry and $66.4 \%$ were sponsored by others, including academic groups. The most common study region explored in the eligible trials was the US (67.1\%), followed by Europe (23.5\%) and Asia (9.4\%).

The characteristics of the trials conducted in the last decade versus those conducted before 2008 are shown in Table 2. Compared with trials registered before 2008, those registered in the last 10 years were significantly more likely to be phase III $(p=0.048)$. In addition, in the last decade, sarcoma studies were more likely to contain more than 2 arms $(17.7 \%$ vs $35.3 \% ; p=0.007)$ and to be randomized $(13.5 \%$ vs $30.4 \% ; p=$ $0.002)$ and double-blinded ( $2.1 \%$ vs $9.4 \% ; p=0.024)$. We also
Table 1 Trials characteristics

\begin{tabular}{|c|c|c|}
\hline & Number & Percent \\
\hline \multicolumn{3}{|l|}{ Trial phase } \\
\hline Phase I/II & 48 & 17.3 \\
\hline Phase II & 200 & 72.2 \\
\hline Phase II/III & 4 & 1.4 \\
\hline Phase III & 25 & 9.0 \\
\hline \multicolumn{3}{|l|}{ Sponsor } \\
\hline $\mathrm{NIH}$ & 33 & 11.9 \\
\hline Industry & 60 & 21.7 \\
\hline Other & 184 & 66.4 \\
\hline \multicolumn{3}{|l|}{ Enrollment size } \\
\hline $0-50$ & 136 & 49.1 \\
\hline $51-100$ & 65 & 23.5 \\
\hline $101-200$ & 40 & 14.4 \\
\hline $201-300$ & 6 & 2.2 \\
\hline 301-more & 16 & 5.8 \\
\hline NR & 14 & 5.1 \\
\hline \multicolumn{3}{|l|}{ Number of centers } \\
\hline 1 & 97 & 35.0 \\
\hline 2 & 6 & 2.2 \\
\hline multicenter & 174 & 62.8 \\
\hline \multicolumn{3}{|l|}{ Number of arms } \\
\hline 1 & 196 & 70.8 \\
\hline 2 & 67 & 24.2 \\
\hline$\geq 3$ & 14 & 5.1 \\
\hline \multicolumn{3}{|c|}{ Treatment allocation } \\
\hline Non-randomized & 209 & 75.5 \\
\hline Randomized & 68 & 24.5 \\
\hline \multicolumn{3}{|l|}{ Masking } \\
\hline Open-label & 257 & 6.9 \\
\hline Single-blind & 1 & 0.4 \\
\hline Double-blind & 19 & 92.8 \\
\hline \multicolumn{3}{|l|}{ Region } \\
\hline United states & 186 & 67.1 \\
\hline Europe & 65 & 23.5 \\
\hline Asia & 26 & 9.4 \\
\hline
\end{tabular}

Trial characteristics are based on the clinical trials which are advanced or metastatic sarcoma specific. Abbreviations: NIH National Institutes of Health, NR null value

sought to identify trends in clinical trial treatments over this period. In the past 10 years, metastatic or advanced sarcoma clinical trials were more likely to involve target therapy and immunotherapy $(71.8 \%$ vs $37.5 \%$; $p<0.001)$ (Table 2$)$. The percentage of trials involving immunotherapy increased from $12.5 \%$ in 2007 to $43.6 \%$ in 2017 . The proportion of adult clinical sarcoma trials initiated in Asia increased from $0 \%$ in 2007 to $28.2 \%$ in 2017 (Fig. 2). 
Table 2 Baseline characteristics of clinical trials associated with the changing year $(n=277)$

\begin{tabular}{|c|c|c|c|}
\hline \multirow[t]{2}{*}{ Characteristics } & \multicolumn{2}{|l|}{ Number of trials (\%) } & \multirow[t]{2}{*}{$P$ value } \\
\hline & Before to 2007 year & 2008-2017 year & \\
\hline Trial phase & & & 0.048 \\
\hline Phase I/II & $10(10.4)$ & $38(21.0)$ & \\
\hline Phase II & $78(81.3)$ & $122(67.4)$ & \\
\hline Phase II/II & $0(0)$ & $4(2.2)$ & \\
\hline Phase III & $8(8.3)$ & $17(9.4)$ & \\
\hline Sponsor & & & 0.215 \\
\hline $\mathrm{NIH}$ & $16(16.7)$ & $17(9.4)$ & \\
\hline Industry & $20(20.8)$ & $40(22.1)$ & \\
\hline Other & $60(62.5)$ & $124(68.5)$ & \\
\hline Number of centers & & & 0.560 \\
\hline 1 & $32(33.3)$ & $65(35.9)$ & \\
\hline 2 & $1(1.0)$ & $5(2.8)$ & \\
\hline multicenter & $63(65.6)$ & $111(61.3)$ & \\
\hline Number of arms & & & 0.007 \\
\hline 1 & 79 (82.3) & $117(64.6)$ & \\
\hline 2 & $13(13.5)$ & $54(29.8)$ & \\
\hline$\geq 3$ & $4(4.2)$ & $10(5.5)$ & \\
\hline Treatment allocation & & & 0.002 \\
\hline Non-randomized & $83(86.5)$ & $126(69.6)$ & \\
\hline Randomized & $13(13.5)$ & $55(30.4)$ & \\
\hline Masking & & & 0.024 \\
\hline Open-label & $94(97.9)$ & 164 (90.6) & \\
\hline Double-blind & $2(2.1)$ & $17(9.4)$ & \\
\hline Region & & & $<0.001$ \\
\hline United states & $77(80.2)$ & $109(60.2)$ & \\
\hline Europe & $18(18.8)$ & $47(26.0)$ & \\
\hline Asia & $1(1.0)$ & $25(13.8)$ & \\
\hline \multicolumn{4}{|l|}{ Therapy } \\
\hline Chemotherapy & $55(57.3)$ & $40(22.1)$ & $<0.001$ \\
\hline Target therapy /immunology therapy & $36(37.5)$ & $130(71.8)$ & \\
\hline other & $5(5.2)$ & $11(6.1)$ & \\
\hline
\end{tabular}

Percentage of trial characteristics with each inclusion criteria group. Chi-squared test was used for class variables NIH, National Institutes of Health

\section{Multi-RTK and VEGFR are prime targets in phase II/III clinical trials of advanced soft tissue sarcoma}

Among the 277 eligible clinical trials, 128 trials were identified to involve target therapy among the metastatic or advanced sarcoma trials. An overview of all the targeted therapy receptors is presented in Table 3.

In the present study, we found that a growing number of multiple-RTK inhibitors are being tested for sarcoma treatment $(40,31.3 \%)$. This type of target agent included imatinib, sunitinib, sorafenib, pazopanib, regorafenib, anlotinib, etc. Particularly, pazopanib acts as a novel TKI and plays a key role in a broad spectrum of tumour types $(13 / 40,32.5 \%)$ during these trials. We also found that some clinical trials focused on the target VEGFR, which plays a central role in tumour angiogenesis and metastasis (17, 13.3\%). The other studied targeted receptors or pathways were mTOR (12, 9.4\%), HDAC (9, 7.0\%), CDK (4, 7\%) IGF-1R (5, 3.9\%) and PDGFR (5, 3.9\%).

Furthermore, the proportion of clinical trials focused on target therapy that were initiated in Asia increased in the past 10 years compared with clinical trials initiated before 2008 (0 vs 12). In particular, anlotinib (NCT02449343, NCT01878448) and apatinib (NCT0312846, NC03064243, 
NCT03104335, NCT02711007, NCT03163381) are two typical representatives of multi-RTK inhibitors and VEGFR inhibitors that were developed in China.

The trials involving two target drugs are presented in Table 4. These trials were all conducted in the past 10 years, with seven conducted in the US and one conducted in Europe.

\section{Immune checkpoint inhibition therapies contributed} greatly in all clinical trials that evaluated immunotherapy Thirty-three trials evaluated immunotherapy in metastatic or advanced sarcoma. Seventeen trials explored the role of immune checkpoint receptors (51.5\%). Among them, 11 trials focused on the PD1 antibody (NCT0321745, NCT0312376, NCT3013127, NCT03056001, NCT3138061, NCT3069378, NCT02888665, NCT02691026, NCT02406781, NCT2301039, NCT03282344). Four trials evaluated anti-PD-L1 therapy (NCT03141684, NCT03074318, NCT03233698, NCT02609984), and two trials used the PD1 antibody combined with the CTLA-4 antibody as treatment (NCT02982486, NCT02428192). Seven $(21.2 \%)$ trials evaluated vaccines as interventions in sarcoma. Five (15.2\%) trials evaluated adoptive cell transfer as a treatment in advanced sarcoma patients. Only two (6.1\%) of the eligible trials explored immunomodulators and oncolytic viruses (Table 5). The number of clinical trials focused on immunotherapy is not large compared with the number of clinical trials focused on target therapies, but the number of trials focusing on immunotherapy grew significantly since 2014 (Fig. 2). These results indicated that immunotherapy, especially the anti-PD1/PDL1 pathway, could be a trend in STS treatment. in STS.

\section{The combination of immunotherapy and target therapy has increased in recent years}

Because target therapy and immunotherapy are trends in sarcoma research, we evaluated the treatment combining immunotherapy with target therapy in advanced sarcoma patients. All five trials evaluated the PD1 antibody combined with targeted drugs, and one trial evaluated nivolumab combined with pazopanib in soft-tissue sarcoma (NCT03149120); one trial evaluated nivolumab combined with the mTOR inhibitor rapamycin in undifferentiated pleomorphic sarcoma, liposarcoma, chondrosarcoma, osteosarcoma and Ewing's sarcoma (NCT03190174); one trial explored the role of the combination of pembrolizumab with axitinib in mostly alveolar soft-tissue sarcoma (NCT02636725); one trial evaluated nivolumab combined with sunitinib in soft-tissue sarcoma (NCT03277924); and the last trial, which is an open-label, phase II trial located in China, studied anti-PD1 therapy (camrelizumab) plus apatinib mesylate in locally advanced, unresectable or metastatic osteosarcoma (Table 6).

\section{Discussion}

The development of new systemic treatments for soft-tissue sarcomas has progressed little in the past few decades, except for treatments for gastrointestinal stromal tumours. Patients with metastatic soft-tissue sarcomas have a median overall

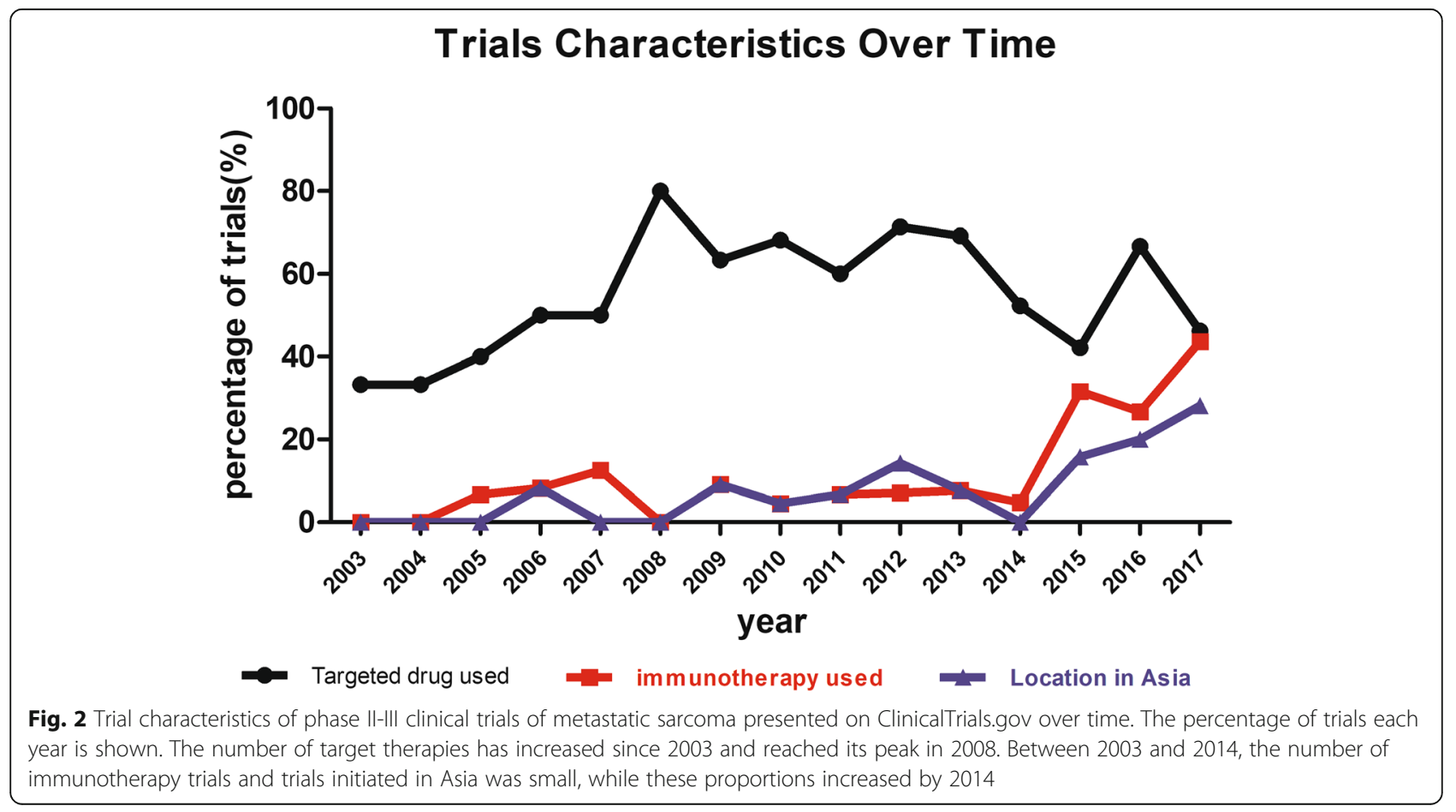


Table 3 Target therapy clinical trials related to phase II \& III advanced or metastatic sarcoma

\begin{tabular}{|c|c|c|}
\hline Targets & Trials (n) & $\%$ \\
\hline Multi-RTK & 40 & 31.3 \\
\hline VEGFR & 17 & 13.3 \\
\hline mTOR & 12 & 9.4 \\
\hline HDAC & 9 & 7.0 \\
\hline Combination targets & 8 & 6.3 \\
\hline CDK & 6 & 4.7 \\
\hline IGF-1R & 5 & 3.9 \\
\hline PDGFR & 5 & 3.9 \\
\hline Hedgehog & 3 & 2.3 \\
\hline AKT & 2 & 1.6 \\
\hline CD105 & 2 & 1.6 \\
\hline EGFR & 2 & 1.6 \\
\hline HER2 & 2 & 1.6 \\
\hline Hypoxic region & 2 & 1.6 \\
\hline MET & 2 & 1.6 \\
\hline 265 proteasome & 1 & $<1$ \\
\hline Aurora A & 1 & $<1$ \\
\hline CRM1 & 1 & $<1$ \\
\hline DR5 & 1 & $<1$ \\
\hline Endoglin & 1 & $<1$ \\
\hline Endosialin/TEM1 & 1 & $<1$ \\
\hline G6PD & 1 & $<1$ \\
\hline PPAR- $\gamma$ & 1 & $<1$ \\
\hline SRC & 1 & $<1$ \\
\hline Tie2 & 1 & $<1$ \\
\hline$\beta$-receptor & 1 & $<1$ \\
\hline
\end{tabular}

The different targets of 128 registered clinical trials. RTK, receptor tyrosine kinase; VEGFR, vascular endothelial growth factor receptor; HDAC, histone deacetylase; CDK, cyclin-dependent kinase; IGF-1R, insulin-like growth factor 1 receptor; PDGFR, platelet-derived growth factor receptor; AKT, protein kinase $B$; EGFR, epidermal growth factor receptor; HER2, human epidermal growth factor receptor 2; MET, a receptor tyrosine kinase that is produced as a singlechain precursor; CRM1, chromosomal maintenance 1; DR5, death receptor-5; G6PD, glucose-6-phosphate dehydrogenase; PPAR- $\gamma$, peroxisome proliferatoractivated receptors; SRC, proto-oncogene tyrosine-protein kinase; Tie2, tyrosine kinase with immunoglobulin-like and EGF-like domains 1

survival of approximately 12 months $[6,13]$. Primarily, chemotherapy with doxorubicin and/or ifosfamide is a common approach, but some subtypes are resistant to chemotherapy [14]. The combination of gemcitabine and docetaxel is mainly used in leiomyosarcomas, and some retrospective analyses have confirmed the activity of this regimen in undifferentiated pleomorphic sarcomas of metastatic patients $[15,16]$. In addition, trabectedin has been demonstrated to achieve a dimensional response or disease stability in more than $40 \%$ of patients, as evidenced by the longer OS in so-called L-sarcoma (liposarcoma and leiomyosarcoma) [17]. From these results, different cytotoxic drugs have shown specific activity in selective histotypes. However, many patients ultimately die because of limited alternate chemotherapeutic regimens for recurrent and metastatic diseases [18]. Thus, novel agents with new therapies and rigorous prospective clinical trials are desperately needed to validate the role of innovative strategies.

Our study demonstrated that sarcoma trials in the last 10 years were predominantly late-phase studies with a generally high proportion of multi-arm, randomized and double-blind studies. The most likely cause for this trend is the development of new monitoring processes to improve randomized trial performance, data collection and good clinical practice (GCP) compliance, such as PRIME-Peer Review Intervention for Monitoring and Evaluating sites [19]. Our analysis confirms the critical role for science in the establishment and performance of clinical trials. These findings likely reflect the trend and necessity for developing more randomized and double-blinded studies under GCP management.

We also found the growing role of target therapy and immunotherapy in bone and soft-tissue sarcoma trials by evaluating a comprehensive landscape. This may be the result of an increasing number of RTKs and other small molecular inhibitors that have been developed, and evidence is emerging that targeting RTKs and other small molecular inhibitors could be an effective approach. In the past few years, research on sarcoma has mostly focused on the molecular aspects of tumourigenesis [20,21]. Imatinib was the first target TKI developed and approved by the Food and Drugs Administration (FDA) and European Medicines Agency (EMA). Adjuvant imatinib significantly improved recurrence-free survival compared with placebo (98\% [95\%CI 96-100] vs 83\% [78-88] at 1 year after the resection of primary GIST [22]. After the production of imatinib, other promising TKIs have been utilized in clinical trials and released to the market, including sunitinib (NCT00400569, NCT00474994), sorafenib (NCT00238121, NCT00245102, NCT00217620) and pazopanib (NCT00753688). Pazopanib showed promising potential in the treatment of patients with STS. In the randomized, double-blind clinical trial (PALETTE-EORTC 62072), patients with metastatic STS of various histologies were randomly assigned to receive pazopanib or placebo. The results showed that the median progression-free survival was 4.6 months for the pazopanib group compared with 1.6 months for the placebo group, which indicated that pazopanib is a promising treatment option for patients with STS [6]. Thus, the US FDA and EMA approved pazopanib for use in the second or further line of treatment of patients with nonadipogenic STS [23]. Moreover, sarcoma trials are a new trend in Asia. Anlotinib is a novel multi-TKI that has been initiated in clinical trials in China and has shown some antitumour activity in several STS entities, including leiomyosarcoma (LMS), synovial sarcoma (SS) and alveolar soft tissue sarcoma (ASPS) [24]. Recently, a growing number of phase II/ 
Table 4 Combination of two targeted drug Trials

\begin{tabular}{|c|c|c|c|c|c|c|c|}
\hline NCT No. & Drug1 & Drug2 & Targets & Year & Phase & Region & Results \\
\hline NCT03114527 & Ribociclib & Everolimus & CDK, mTOR & 2017 & Phase II & US & No \\
\hline NCT02343172 & HDM201 & LEE011 & $\mathrm{MDM} 2, \mathrm{CDK}$ & 2015 & Phase \| Phase \| & US & No \\
\hline NCT02008877 & ganetespib & Sirolimus & HSP90, CD105 & 2013 & Phase I|Phase ॥ & US & No \\
\hline NCT01804374 & Sorafenib & Everolimus & Multi-RTK, mTOR & 2011 & Phase II & Europe & No \\
\hline NCT01281865 & everolimus & imatinib & Multi-RTK, mTOR & 2011 & Phase I|Phase \| & US & Yes \\
\hline NCT01206140 & Selumetinib & Temsirolimus & MEK, mTOR & 2010 & Phase II & US & Yes \\
\hline NCT01016015 & Cixutumumab & Temsirolimus & mTOR, IGF-1R & 2009 & Phase II & US & Yes \\
\hline NCT00937495 & vorinostat & bortezomib & HDAC,26S proteasome & 2009 & Phase II & US & Yes \\
\hline
\end{tabular}

Abbreviations: CDK cyclin-dependent kinase, mTOR mammalian target of rapamycin, MDM2 Mouse double minute 2 homolog, HSP90 heat shock protein $90, R T K$ receptor tyrosine kinase, MEK Mitogen-activated protein kinase kinase, IGF-1R Insulin-like growth factor 1 receptor, HDAC Histone deacetylase

III clinical trials of apatinib, which is a new type of VEGFR inhibitor for sarcomas, have also been initiated in China (NCT0312846, NC03064243, NCT03104335, NCT027 11007, NCT03163381). In addition, clinical trials focusing on other promising VEGFR inhibitors, such as cabozantinib (NCT01755195, NCT01979393), and tivozanib (NCT01782313), are ongoing and recruiting patients. It is notable that doxorubicin combined with olaratumab, the monoclonal antibody that specifically binds PDGFR, showed promising improvement in overall survival in patients with advanced STS compared with doxorubicin alone (NCT01185964). The rising trend of target therapy in sarcoma indicates a step forward in the concept of new developments in molecular targeted agents that significantly change the medical approach towards STS.

Additionally, a growing number of clinical trials investigating immunotherapy, particularly immune checkpoint inhibitors, are currently ongoing thanks to the success of anti-PD1 therapy in other tumours, including melanoma and NSCLC. Sarcomas are among the first tumours to be considered for immunotherapy [25]. From Coley's toxin to adoptive cell therapy to immune checkpoint inhibitors, immunologic treatments hold substantial potential in sarcoma. In a randomized, double-blind phase study (SARC028), pembrolizumab suggested a potential benefit for undifferentiated pleomorphic sarcoma with a response rate of $40 \%$ while having little clinical effect in synovial sarcoma and myxoid/ round cell liposarcoma due to many factors, including

Table 5 Immunotherapy Trials

\begin{tabular}{lll}
\hline Immunotherapy & Trials $(\mathrm{n})$ & $\%$ \\
\hline Immune checkpoint inhibitors & 17 & 51.5 \\
Vaccine & 7 & 21.2 \\
Adoptive cell transfer & 5 & 15.2 \\
Immunomodulator $^{\mathrm{a}}$ & 2 & 6.1 \\
Oncolytic virus & 2 & 6.1 \\
\hline
\end{tabular}

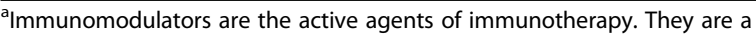
diverse array of recombinant, synthetic, and natural preparations including interleukins, cytokines, chemokines
PD-L1 expression, tumour mutation burden, T-cell infiltration, etc. CTLA-4 is a key protein during the priming phase of the immune system, and its inhibition is thought to increase $\mathrm{T}$ cells in circulation and deplete Tregs. A blockade of the PD-1/PD-L1 axis results in a profound tumour response that could occur as early as 8-12 weeks. Thus, the combination of an anti-PD-1 and anti-CTLA-4 strategy indicates longer-lasting activity. Currently, the combination of two checkpoint inhibitors has already resulted in improved outcomes with melanoma [26]. Given its mechanism and clinical benefit in melanoma, trials involving dual blockade with PD-1/ PD-L1 and cytotoxic T-lymphocyte-associated protein 4 inhibitors in sarcoma are ongoing (NCT02428192, NCT02982486). Talimogene laherparepvec (T-VEC) combined with pembrolizumab demonstrated acceptable safety and promising anti-tumor activity across a range of sarcoma histologies with 4 patients maintain PR (NCT03069378). In addition to immune checkpoint inhibitors, dendritic cell (DC)-based therapies have yet to show clinical efficacy in bony or soft-tissue sarcomas [27, 28]. An open label, phase I/II study evaluated the PFS of patients receiving autologous dendritic cell vaccine loaded with allogeneic tumor lysate expression of cancer-testis antigens in patients with STS (NCT01883518). Adoptive cellular therapy targeting NY-ESO-1-expressing synovial and myxoid/round cell liposarcoma has shown some efficacy $[29,30]$. Thus, future clinical studies related to immunotherapy will hopefully further need to identify the appropriate population that will benefit from this therapy.

Importantly, novel combinations of immune-target therapies are emerging to explore whether the targeted drugs may assist in inducing consistent and durable immune responses. For example, blockade of mTOR combined with nivolumab is being tested for antitumour activity in sarcoma (NCT03190174). Axitinib, an RTK inhibitor reported to induce T-cell trafficking, is applied with pembrolizumab in sarcoma (NCT02636725). Sunitinib plus nivolumab induced objective responses in several sarcoma types with 10 patients 
Table 6 Combination of target therapy and immunotherapy

\begin{tabular}{|c|c|c|c|c|c|c|c|}
\hline NCT No. & Drug 1 & Drug2 & Conditions & Phase & region & $\begin{array}{l}\text { Start } \\
\text { year }\end{array}$ & results \\
\hline NCT03149120 & Nivolumab & Pazopanib & Soft Tissue Sarcomas & Phase II & US & 2017 & No \\
\hline NCT03190174 & Nivolumab & Rapamycin & $\begin{array}{l}\text { Undifferentiated Pleomorphic } \\
\text { Sarcoma|Liposarcoma|Chondrosarcoma|Osteosarcoma|Ewing } \\
\text { Sarcoma }\end{array}$ & $\begin{array}{l}\text { Phase II } \\
\text { Phase II }\end{array}$ & US & 2017 & No \\
\hline NCT02636725 & Pembrolizumab & Axitinib & Alveolar Soft Part Sarcoma|Soft Tissue Sarcomas & Phase II & US & 2016 & No \\
\hline NCT03359018 & Camrelizumab & Apatinib & osteosarcoma & Phase II & Asia & 2018 & No \\
\hline NCT03277924 & Nivolumab & Sunitinib & Soft Tissue Sarcoma|Bone Sarcoma & $\begin{array}{l}\text { Phase I| } \\
\text { Phase II }\end{array}$ & Europe & 2017 & No \\
\hline
\end{tabular}

Note: Nivolumab and pembrolizumab are PD-1 antibodies while camrelizumab is PD-L1 antibody

achieved disease control (71.4\%), including clear cell sarcoma (2 PR), angiosarcoma (1 PR), differentiated chondrosarcoma (1 PR), synovial sarcoma (1 PR), alveolar soft part sarcoma (1 PR) (NCT03277924).

Although our study is unique, there are some limitations in this analysis that are worth noting. First, phase I studies were excluded because of the heterogeneity of phase I trials and their typical focus on the use of safety end points. Second, ClinicalTrials.gov does not include all trials performed worldwide. Clinical trials not registered in clinical trial.gov could be found in Pubmed or through conference meetings. However, many of these trials are pilot studies and the impact is small. Additionally, trials may not have been included in our database if essential keywords were not included upon registration, and misclassification may lead to an inappropriate conclusion. However, our screening process attempted to minimize the potential biases. All the studies were reviewed by 2 physicians independently.

\section{Conclusions}

To our knowledge, this is the first analysis to comprehensively define the landscape of metastatic sarcoma trials over the last 2 decades. A concerted effort among the NIH, industry and academia is required to increase the quality and quantity of clinical trials of sarcoma with a significant goal of improving the identification and delivery of effective therapies for patients with sarcoma.

\section{Additional file}

Additional file 1: Information of 277 eligible Trials with ClinicalTrials.gov identification numbers in this study. (XLSX $96 \mathrm{~kb}$ )

\footnotetext{
Abbreviations

CDK: cyclin-dependent kinases; CTLA-4: cytotoxic T-lymphocyte-associated protein 4; EMA: European Medicines Agency; FDA: Food and Drug Administration; GIST: gastrointestinal stromal tumours; HDAC: histone deacetylase; IGF1R: insulin-like growth factor 1 receptor; LAG-3: Lymphocyteactivation protein 3; NIH: National Institutes of Health; PD1: programmed cell death protein 1; PDGFR: platelet-derived growth factor receptor; PDL1: programmed death-ligand 1; RTKs: receptor tyrosine kinase; STS: soft tissue sarcoma; Tim-3: T cell immunoglobulin mucin-3; VEGFR: vascular endothelial growth factor receptor; WHO: World Health Organization
}

Acknowledgements

We wish to thank all the contributors for their help with the conception and revision of the manuscript.

\section{Funding}

This work was supported by National Scientific Foundation of China (No. 81572403 and No. 81772863) and the National Basic Research Program of China (Grant No. 2013CB910500).

\section{Availability of data and materials}

The datasets analysed in the current study are available from the corresponding author on reasonable request. Anyone who is interested in the information should contact zhangxing@sysucc.org.cn.

\section{Authors' contributions}

$\mathrm{XZ}$ is responsible for the study design and revised the manuscript. YQ participated in data collection, analysis and manuscript writing. WX participated in data collection and interpretation of the manuscript. BSX assisted in analysis and preparation of the manuscript. XZW provided guidance in statistical analysis and DSW reviewed the manuscript for intellectual content. All authors read and approved the final manuscript.

Ethics approval and consent to participate

Not applicable.

Consent for publication

Not applicable.

\section{Competing interests}

The authors declare that they have no competing interests.

\section{Publisher's Note}

Springer Nature remains neutral with regard to jurisdictional claims in published maps and institutional affiliations.

Received: 23 May 2018 Accepted: 29 November 2018

Published online: 13 December 2018

\section{References}

1. Clark MA, Fisher C, Judson I, Thomas JM. Soft-tissue sarcomas in adults. N Engl J Med. 2005;353(7):701-11.

2. Casali PG, Blay JY, Experts ECECPo. Soft tissue sarcomas: ESMO clinical practice guidelines for diagnosis, treatment and follow-up. Ann Oncol. 2010; 21(Suppl 5):v198-203.

3. Ducimetiere F, Lurkin A, Ranchere-Vince D, Decouvelaere AV, Peoc'h M, Istier L, Chalabreysse P, Muller C, Alberti L, Bringuier PP, et al. Incidence of sarcoma histotypes and molecular subtypes in a prospective epidemiological study with central pathology review and molecular testing. PLoS One. 2011;6(8):e20294.

4. Sleijfer S, Ouali M, van Glabbeke M, Krarup-Hansen A, Rodenhuis S, Le Cesne A, Hogendoorn PC, Verweij J, Blay JY. Prognostic and predictive factors for outcome to first-line ifosfamide-containing chemotherapy for adult patients with advanced soft tissue sarcomas: an exploratory, retrospective analysis 
on large series from the European Organization for Research and Treatment of Cancer-soft tissue and bone sarcoma group (EORTC-STBSG). Eur J Cancer. 2010;46(1):72-83.

5. Chinese Journal of $\mathrm{C}$, editor. The 150 most important questions in cancer research and clinical oncology series: questions 31-39: Edited by Chinese Journal of Cancer. Chin J Cancer. 2017:36(1):48.

6. van der Graaf WT, Blay JY, Chawla SP, Kim DW, Bui-Nguyen B, Casali PG, Schoffski P, Aglietta M, Staddon AP, Beppu Y, et al. Pazopanib for metastatic soft-tissue sarcoma (PALETTE): a randomised, double-blind, placebocontrolled phase 3 trial. Lancet. 2012;379(9829):1879-86.

7. D'Angelo SP, Tap WD, Schwartz GK, Carvajal RD. Sarcoma immunotherapy: past approaches and future directions. Sarcoma. 2014;2014:391967.

8. Lim J, Poulin NM, Nielsen TO. New strategies in sarcoma: linking genomic and immunotherapy approaches to molecular subtype. Clin Cancer Res. 2015;21(21):4753-9.

9. Pao W, Girard N. New driver mutations in non-small-cell lung cancer. Lancet Oncol. 2011;12(2):175-80.

10. Hodis E, Watson IR, Kryukov GV, Arold ST, Imielinski M, Theurillat JP, Nickerson E, Auclair D, Li L, Place C, et al. A landscape of driver mutations in melanoma. Cell. 2012;150(2):251-63.

11. Califf RM, Zarin DA, Kramer JM, Sherman RE, Aberle LH, Tasneem A. Characteristics of clinical trials registered in ClinicalTrials.gov, 2007-2010. JAMA. 2012:307(17):1838-47.

12. Wishart DS, Knox C, Guo AC, Shrivastava S, Hassanali M, Stothard P, Chang Z, Woolsey J. DrugBank: a comprehensive resource for in silico drug discovery and exploration. Nucleic Acids Res. 2006;34(Database issue):D668-72.

13. Tap WD, Jones RL, Van Tine BA, Chmielowski B, Elias AD, Adkins D, Agulnik M, Cooney MM, Livingston MB, Pennock $G$, et al. Olaratumab and doxorubicin versus doxorubicin alone for treatment of soft-tissue sarcoma: an open-label phase $1 \mathrm{~b}$ and randomised phase 2 trial. Lancet. 2016; 388(10043):488-97.

14. Judson I, Verweij J, Gelderblom H, Hartmann JT, Schoffski P, Blay JY, Kerst JM, Sufliarsky J, Whelan J, Hohenberger $P$, et al. Doxorubicin alone versus intensified doxorubicin plus ifosfamide for first-line treatment of advanced or metastatic soft-tissue sarcoma: a randomised controlled phase 3 trial. Lancet Oncol. 2014;15(4):415-23.

15. Bay JO, Ray-Coquard I, Fayette J, Leyvraz S, Cherix S, Piperno-Neumann S, Chevreau C, Isambert N, Brain E, Emile G, et al. Docetaxel and gemcitabine combination in 133 advanced soft-tissue sarcomas: a retrospective analysis. Int J Cancer. 2006;119(3):706-11.

16. Schmitt T, Kosely F, Wuchter P, Schmier JW, Ho AD, Egerer G. Gemcitabine and docetaxel for metastatic soft tissue sarcoma - a single center experience. Onkologie. 2013;36(7-8):415-20.

17. Samuels BL, Chawla S, Patel S, von Mehren M, Hamm J, Kaiser PE, Schuetze $\mathrm{S}$, Li J, Aymes A, Demetri GD. Clinical outcomes and safety with trabectedin therapy in patients with advanced soft tissue sarcomas following failure of prior chemotherapy: results of a worldwide expanded access program study. Ann Oncol. 2013;24(6):1703-9.

18. Maki RG. Gemcitabine and docetaxel in metastatic sarcoma: past, present, and future. Oncologist. 2007;12(8):999-1006.

19. Lane JA, Wade J, Down L, Bonnington S, Holding PN, Lennon T, Jones AJ, Salter CE, Neal DE, Hamdy FC, et al. A peer review intervention for monitoring and evaluating sites (PRIME) that improved randomized controlled trial conduct and performance. J Clin Epidemiol. 2011;64(6):628-36.

20. Casali PG. Histology- and non-histology-driven therapy for treatment of soft tissue sarcomas. Ann Oncol. 2012;23(Suppl 10):×167-9.

21. Husain N, Verma N. Curent concepts in pathology of soft tissue sarcoma. Indian J Surg Oncol. 2011;2(4):302-8.

22. Dematteo RP, Ballman KV, Antonescu CR, Maki RG, Pisters PW, Demetri GD, Blackstein ME, Blanke CD, von Mehren M, Brennan MF, et al. Adjuvant imatinib mesylate after resection of localised, primary gastrointestinal stromal tumour: a randomised, double-blind, placebo-controlled trial. Lancet. 2009;373(9669):1097-104.

23. Ranieri G, Mammi M, Donato Di Paola E, Russo E, Gallelli L, Citraro R, Gadaleta CD, Marech I, Ammendola M, De Sarro G. Pazopanib a tyrosine kinase inhibitor with strong anti-angiogenetic activity: a new treatment for metastatic soft tissue sarcoma. Crit Rev Oncol Hematol. 2014;89(2):322-9.

24. Chi Y, Fang Z, Hong $X$, Yao $Y$, Sun $P$, Wang G, Du F, Sun Y, Wu Q, Qu G, et al. Safety and efficacy of Anlotinib, a multikinase angiogenesis inhibitor, in patients with refractory metastatic soft-tissue sarcoma. Clin Cancer Res. 2018;24(21):5233-8.
25. Coley WB. II. Contribution to the knowledge of sarcoma. Ann Surg. 1891; 14(3):199-220.

26. Wolchok JD, Kluger $H$, Callahan MK, Postow MA, Rizvi NA, Lesokhin AM, Segal NH, Ariyan CE, Gordon RA, Reed K, et al. Nivolumab plus ipilimumab in advanced melanoma. N Engl J Med. 2013;369(2):122-33.

27. Miwa S, Nishida H, Tanzawa Y, Takeuchi A, Hayashi K, Yamamoto N, Mizukoshi E, Nakamoto Y, Kaneko S, Tsuchiya H. Phase 1/2 study of immunotherapy with dendritic cells pulsed with autologous tumor lysate in patients with refractory bone and soft tissue sarcoma. Cancer. 2017;123(9):1576-84.

28. Krishnadas DK, Shusterman S, Bai F, Diller L, Sullivan JE, Cheerva AC, George RE, Lucas KG. A phase I trial combining decitabine/dendritic cell vaccine targeting MAGE-A1, MAGE-A3 and NY-ESO-1 for children with relapsed or therapy-refractory neuroblastoma and sarcoma. Cancer Immunol Immunother. 2015;64(10):1251-60.

29. Robbins PF, Morgan RA, Feldman SA, Yang JC, Sherry RM, Dudley ME, Wunderlich JR, Nahvi AV, Helman $\sqcup$, Mackall CL, et al. Tumor regression in patients with metastatic synovial cell sarcoma and melanoma using genetically engineered lymphocytes reactive with NY-ESO-1. J Clin Oncol. 2011;29(7):917-24.

30. Robbins PF, Kassim SH, Tran TL, Crystal JS, Morgan RA, Feldman SA, Yang JC, Dudley ME, Wunderlich JR, Sherry RM, et al. A pilot trial using lymphocytes genetically engineered with an NY-ESO-1-reactive T-cell receptor: long-term follow-up and correlates with response. Clin Cancer Res. 2015;21(5):1019-27.

\section{Ready to submit your research? Choose BMC and benefit from:}

- fast, convenient online submission

- thorough peer review by experienced researchers in your field

- rapid publication on acceptance

- support for research data, including large and complex data types

- gold Open Access which fosters wider collaboration and increased citations

- maximum visibility for your research: over $100 \mathrm{M}$ website views per year

At BMC, research is always in progress.

Learn more biomedcentral.com/submissions 